Pacific Journal of Mathematics

PARTIAL DIFFERENTIAL EQUATIONS OF
SOBOLEV-GALPERN TYPE R er 


\title{
PARTIAL DIFFERENTIAL EQUATIONS OF SOBOLEV-GALPERN TYPE
}

R. E. SHOWALTER

\begin{abstract}
A mixed initial and boundary value problem is considered for a partial differential equation of the form $M u_{t}(x, t)+L u(x, t)=0$, where $M$ and $L$ are elliptic differential operators of orders $2 \mathrm{~m}$ and $2 l$, respectively, with $m \leqq l$. The existence and uniqueness of a strong solution of this equation in $H_{0}^{l}(G)$ is proved by semigroup methods.
\end{abstract}

We are concerned here with a mixed initial boundary value problem for the equation

$$
M u_{t}+L u=0
$$

in which $M$ and $L$ are elliptic differential operators. Equations of this type have been studied using various methods in $[2,3,4,6,7,10,11$, $13,14,15,17,18]$. We will make use of the $L^{2}$-estimates and related results on elliptic operators to obtain a generalized solution to this problem similar to that obtained for the parabolic equation

$$
u_{t}+L u=0
$$

as in [7].

Let $G$ be a bounded open domain in $R^{n}$ whose boundary $\partial G$ is an $(n-1)$-dimensional manifold with $G$ lying on one side of $\partial G$. By $H^{k}(G) \equiv H^{k}$ we mean the Hilbert space (of equivalence classes) of functions in $L^{2}(G)$ whose distributional derivatives through order $k$ belong to $L^{2}(G)$ with the inner product and norm given, respectively, by

$$
(f, g)_{k}=\sum\left\{\int_{G} D^{\alpha} f \overline{D^{\alpha} g} d x:|\alpha| \leqq k\right\}
$$

and

$$
\|f\|_{k}=\sqrt{(f, f)_{k}} .
$$

$H_{0}^{k} \equiv H_{0}^{k}(G)$ will denote the closure in $H^{k}$ of $C_{0}^{\infty}(G)$, the space of infinitely differentiable functions with compact support in $G$.

The operators are of the form

$$
M=\sum\left\{(-1)^{|\rho|} D^{o} m^{\rho \sigma}(x) D^{\sigma}:|\rho|,|\sigma| \leqq m\right\}
$$

and

$$
L=\sum\left\{(-1)^{|\rho|} D^{\rho} l^{\rho \sigma}(x) D^{\sigma}:|\rho|,|\sigma| \leqq l\right\},
$$


and they are uniformly strongly elliptic in $G$. We shall investigate the existence and uniqueness of solutions to (1) which coincide with the initial function $u_{0}$ in $H_{0}^{l}$ where $t=0$ and vanish on $\partial G$ together with all derivatives of order less than or equal to $l-1$.

If the order of $M$ is as high as that of $L(2 m \geqq 2 l)$, then this problem can be handled as in [10] by forming the exponential of the bounded extension of $M^{-1} L$ on $H_{0}^{m}$ and thus obtaining a group of operators on $H_{0}^{m}$ and a corresponding solution for all $t$ in $\boldsymbol{R}$. The case we shall consider is that of $m \leqq l$, and this will include the parabolic equation as a special case. We obtain a semi-group of operators on $H_{0}{ }^{m}$ and, hence, a solution for all $t \geqq 0$.

2. In this section we shall formulate the problem. Assume temporarily the following.

$P_{1}^{\prime}$ : The coefficients $m^{\rho \sigma}$ in $M$ belong to $H^{\lfloor\rho \mid}$, and $D^{\circ} m^{\rho \sigma}$ is in $L^{\infty}(G)$ whenever $|\rho| \leqq m$. A similar statement is true for the coefficients in $L$. From $P_{1}^{\prime}$ it follows that the sesqui-linear forms defined on $C_{0}^{\infty}(G)$ by

$$
B_{M}(\varphi, \psi)=\sum\left\{\left(m^{\rho \sigma} D^{o} \varphi, D^{\rho} \psi\right)_{0}:|\rho|,|\sigma| \leqq m\right\}
$$

and

$$
B_{L}(\varphi, \psi)=\sum\left\{\left(l^{\rho \sigma} D^{\sigma} \varphi, D^{\rho} \psi\right)_{0}:|\rho|,|\sigma| \leqq l\right\}
$$

satisfy the identities

$$
B_{M}(\varphi, \psi)=(M \varphi, \psi)_{0}
$$

and

$$
B_{L}(\varphi, \psi)=(L \varphi, \psi)_{0}
$$

for all $\varphi, \psi$ in $C_{0}^{\infty}(G)$. Since $P_{1}^{\prime}$ implies that

$$
K_{m}=\sup \left\{\left\|m^{\rho \sigma}\right\|_{\infty}:|\rho|,|\sigma| \leqq m\right\}
$$

and

$$
K_{l}=\sup \left\{|| l^{\rho \sigma} \|_{\infty}:|\rho|,|\sigma| \leqq l\right\}
$$

are finite, we see that

$$
\left|B_{M}(\varphi, \psi)\right| \leqq K_{m}\|\varphi\|_{m}\|\psi\|_{m}
$$

and

$$
\left|B_{L}(\varphi, \psi)\right| \leqq K_{l}\|\varphi\|_{l}\|\psi\|_{l}
$$

for all $\varphi, \psi$ in $C_{0}^{\infty}(G)$. Hence these sesqui-linear forms may be extended by continuity to all of $H_{0}^{m}$ and $H_{0}^{l}$, respectively. 
The final properties which we shall assume are the following. For any $\varphi, \psi$ in $C_{0}^{\infty}(G)$ we have

$$
\begin{gathered}
P_{2}: \operatorname{Re} B_{M}(\varphi, \varphi) \geqq k_{m}\|\varphi\|_{m}^{2}, k_{m}>0, \\
\operatorname{Re} B_{L}(\varphi, \varphi) \geqq k_{l}\|\varphi\|_{l}^{2}, k_{l}>0,
\end{gathered}
$$

and

$$
P_{3}:\left|B_{M}(\varphi, \psi)\right|^{2} \leqq\left(\operatorname{Re} B_{M}(\varphi, \varphi)\right)\left(\operatorname{Re} B_{M}(\psi, \psi)\right) .
$$

These inequalities are valid for the respective extensions to $H_{0}^{m}$ and $H_{0}^{l}$. The assumptions of $P_{2}$ are inequalities of the Garding type which imply that $M$ and $L$ are uniformly strongly elliptic. Only the first of these is essential in applications, for the usual change of dependent variable $u=v e^{\lambda t}$ changes our equation to one with $L$ replaced by $L+$ $\lambda M$, and the Garding inequality is true for $B_{L+\lambda . M}$ if $\lambda$ is sufficiently large and if the coefficients $l^{\circ \sigma}(x),|\rho|=|\sigma|=l$ are uniformly continuous in $G$. See $[3,8]$ for sufficient conditions that $P_{2}$ be true.

The assumption $P_{3}$ is a Cauchy-Schwarz inequality for the form $B_{M}$. In view of the positivity of $B_{M}$, a necessary and sufficient condition for $P_{3}$ is that $M$ be symmetric, that is, $m^{\rho \sigma}=\overline{m^{\sigma \rho}}$ for all $\rho, \sigma$. Such is the case for the examples

$$
\begin{aligned}
& \text { (i) } k u_{t}-\Delta u=0(m=0) \text { and } \\
& \text { (ii) }-\gamma \Delta u_{t}+k u_{t}-\Delta u=0,
\end{aligned}
$$

where $\Delta$ is the Laplacian and $\gamma$ and $k$ are positive. Example (i) is a parabolic equation, and examples like (ii) appear in various problems of fluid mechanics and soil mechanics, where a solution is sought which satisfies an initial condition $u(x, 0)=u_{0}(x)$ on $G$ and the Dirichlet condition $u(x, t)=0$ on the boundary of $G$. See $[1,11,12,13]$.

We shall not need the full strength of $P_{1}^{\prime}$ so we replace it with the following weaker assumption.

$P_{1}$ : The coefficients $m^{\rho \sigma}$ and $l^{\rho \sigma}$ belong to $L^{\infty}(G)$ for all $\rho, \sigma$. We shall proceed under the assumptions $P_{1}, P_{2}$ and $P_{3}$ and remark that $P_{1}^{\prime}$ is needed only when we wish to interpret our weak solutions by means of (2) and $\left(2^{\prime}\right)$.

Under the hypotheses above there is by the theorem of Lax and Milgram [7] a closed linear operator $M_{0}$ with domain $D_{m}$ dense in $H_{0}^{m}$ and range equal to $H^{0}=L^{2}(G)$ such that

$$
B_{M}(\varphi, \psi)=\left(M_{0} \varphi, \psi\right)_{0}
$$

whenever $\varphi$ belongs to $D_{m}$ and $\psi$ to $H_{0}^{m}$. Furthermore, $M_{0}^{-1}$ is a bounded operator from $H^{0}$ into $H_{0}^{m}$. Similarly, there is a closed linear operator $L_{0}$ with domain $D_{l}$ dense in $H_{0}^{l}$ and range equal to $H^{0}$ with

$$
B_{L}(\varphi, \psi)=\left(L_{0} \varphi, \psi\right)_{0}
$$


whenever $\varphi$ belongs to $D_{l}$ and $\psi$ to $H_{0}^{l}$. Also, $L_{0}^{-1}$ is bounded from $H^{0}$ into $H_{0}^{l}$.

Consider the bijection $A=-M_{0}^{-1} L_{0}$ from $D_{l}$ onto $D_{m}$. For any $\varnothing$ in $D_{m}$ we have

$$
\begin{aligned}
k_{l}\left\|A^{-1} \varphi\right\|_{l}^{2} & =k_{l}\left\|L_{0}^{-1} M_{0} \varphi\right\|_{l}^{2} \\
& \leqq \operatorname{Re} B_{L}\left(L_{0}^{-1} M_{0} \varphi, L_{0}^{-1} M_{0} \varphi\right)=\operatorname{Re}\left(M_{0} \varphi, L_{0}^{-1} M_{0} \varphi\right)_{0} \\
& =\operatorname{Re} B_{M}\left(\varphi, L_{0}^{-1} M_{0} \varphi\right) \leqq K_{m}\|\varphi\|_{m}\left\|A^{-1} \varphi\right\|_{m} \\
& \leqq K_{m}\|\varphi\|_{m}\left\|A^{-1} \varphi\right\|_{l}
\end{aligned}
$$

which yields

$$
\left\|A^{-1} \varphi\right\|_{l} \leqq\left(K_{m} / k_{l}\right)\|\varphi\|_{m}
$$

for all $\varphi$ in $D_{m}$. But $D_{m}$ is dense in $H_{0}^{m}$ so $A^{-1}$ has a unique extension by continuity from $H_{0}^{m}$ onto the set $D=A^{-1}\left(H_{0}^{m}\right)$ in $H_{0}^{l}$, the domain of the closed extension of $A$. The continuity of the injection of $H_{0}^{l}$ into $H_{0}^{m}$ implies that $A^{-1}$ is a bounded operator on $H_{0}^{m}$, and this is the space in which we formulate the Generalized Problem:

For a given initial function $u_{0}$ in $D$, find a differentiable map $u(t)$ of $R^{+}$into $H_{0}^{m}$ for which $u(t)$ belongs to $H_{0}^{l}$ for all $t \geqq 0, u(0)=u_{0}$, and

$$
B_{M}\left(u^{\prime}(t), \varphi\right)+B_{L}(u(t), \varphi)=0
$$

for all $\varphi$ in $C_{0}^{\infty}(G)$ and $t \geqq 0$.

Sufficient conditions for a solution of this generalized problem to be a classical solution will be discussed in [9].

3. The objective of this section is to prove the following results.

THEOREM. There exists a unique solution of the generalized problem. If $u(t)$ is in $D_{l}$ then $u^{\prime}(t)$ is in $D_{m}$ and

$$
M_{0} u^{\prime}(t)+L_{0} u(t)=0
$$

in $H^{\circ}$. The mapping of $u_{0}$ to $u(t)$ is continuous from $H_{0}^{m}$ into itself for each $t \geqq 0$ and furthermore satisfies

$$
\|u(t)\|_{m} \leqq V\left(K_{m} / k_{m}\right)\left\|u_{0}\right\|_{m} \exp \left(-k_{l} t / K_{m}\right) .
$$

We first show that the operator $A$ is the infinitesimal generator of a semi-group of bounded operators on $H_{0}^{m}$; this semi-group will provide a means of constructing a solution to the problem. From the assumptions on $B_{M}$, it follows that the function defined by

$$
|\varphi|_{M}=\sqrt{ }\left(\operatorname{Re} B_{M}(\varphi, \varphi)\right)
$$

is a norm on $H_{0}^{m}$ that is equivalent to the norm $\|\cdot\|_{m}$. In the following we shall use $|\cdot|_{M}$ as the norm on $H_{0}^{m}$, noting further that 


$$
k_{m}^{1 / 2}\|\varphi\|_{m} \leqq|\varphi|_{M} \leqq K_{m}^{1 / 2}\|\varphi\|_{m}
$$

for $\varphi$ in $H_{0}^{m}$.

To obtain the necessary estimates we let $\lambda$ be a nonnegative number and consider the operator $\lambda M_{0}+L_{0}=N$ from the domain $D_{m} \cap D_{l}$ into $H^{0}$. We can define a sesqui-linear form on $D_{m} \cap D_{l}$ by

$$
B_{N}(\varphi, \psi)=\left(\left(\lambda M_{0}+L_{0}\right) \varphi, \psi\right)_{0}=\lambda B_{M}(\varphi, \psi)+B_{L}(\varphi, \psi)
$$

and then note that $B_{N}$ is bounded as well as positive-definite with respect to the norm of $H_{0}^{l}$. We extend $B_{N}$ by continuity to all of $H_{0}^{l}$, and then by the theorem of Lax and Milgram there is a closed linear operator $N_{0}$ from a domain $D_{n}$ in $H_{0}^{l}$ onto $H^{0}$ for which

$$
B_{N}(\varphi, \psi)=\left(N_{0} \varphi, \psi\right)_{0}
$$

whenever $\varphi$ is in $D_{n}$ and $\psi$ in $H_{0}^{l}$. Clearly $N_{0}$ is an extension of $N$ whose domain is $D_{m} \cap D_{l}$.

For all $\varphi$ in $D_{n}$ we have

$$
\begin{aligned}
\operatorname{Re}\left(N_{0} \varphi, \varphi\right)_{0} & =\lambda \operatorname{Re} B_{M}(\varphi, \varphi)+\operatorname{Re} B_{L}(\varphi, \varphi) \\
& \geqq\left(\lambda+k_{l} / K_{m}\right) \operatorname{Re} B_{M}(\varphi, \varphi) \\
& =\left(\lambda+k_{l} / K_{m}\right)|\varphi|_{M}^{2} .
\end{aligned}
$$

Thus, for any $\psi$ in $D_{m}$ we see that $N_{0}^{-1} M_{0} \psi$ belongs to $D_{n}$ and from above

$$
\begin{gathered}
\left(\lambda+k_{l} / K_{m}\right)\left|N_{0}^{-1} M_{0} \psi\right|_{M}^{2} \leqq \operatorname{Re}\left(M_{0} \psi, N_{0}^{-1} M_{0} \psi\right)_{0} \\
\quad=\operatorname{Re} B_{M}\left(\psi, N_{0}^{-1} M_{0} \psi\right) \leqq|\psi|_{M}\left|\left(N_{0}^{-1} M_{0} \psi\right)\right|_{M}
\end{gathered}
$$

by $P_{3}$, so we have obtained the estimate

$$
\left|N_{0}^{-1} M_{0} \psi\right|_{M} \leqq\left(\lambda+k_{l} / K_{m}\right)^{-1}|\psi|_{M}
$$

for all $\psi$ in $D_{m}$.

Letting $\varphi$ be an element of $D_{l} \cap D_{m}$ we see

$$
\begin{aligned}
\left(N_{0}^{-1} M_{0}\right)\left(\lambda+M_{0}^{-1} L_{0}\right) \varphi & =N_{0}^{-1}\left(\lambda M_{0} \varphi+L_{0} \varphi\right) \\
& =N_{0}^{-1} \cdot N \varphi=\varphi,
\end{aligned}
$$

so $\lambda+M_{0}^{-1} L_{0}$ is injective and satisfies

$$
\left(\lambda+M_{0}^{-1} L_{0}\right)^{-1}=N_{0}^{-1} M_{0}
$$

on $D_{m} \cap D_{l}$. Combining this with the estimate above we see that

$$
\left|\left(\lambda+M_{0}^{-1} L_{0}\right)^{-1} \psi\right|_{M} \leqq\left(\lambda+k_{l} / K_{m}\right)^{-1}|\psi|_{M}
$$

for all $\psi$ in $D_{l} \cap D_{m}$. It follows by continuity that $\lambda-A$ is invertible on $H_{0}^{m}$ and satisfies the estimate

$$
\left|(\lambda-A)^{-1}\right|_{M} \leqq\left(\lambda+k_{l} / K_{m}\right)^{-1} \text {. }
$$


By the theorem of Hille and Yoshida $[5,16]$ on the characterization of the infinitesimal generators of semi-groups of class $C_{0}$ we have the following results: there exists a unique family of bounded operators $\{S(t): t \geqq 0\}$ on $H_{0}^{m}$ for which

(i) $S\left(t_{1}+t_{2}\right)=S\left(t_{1}\right) S\left(t_{2}\right)$,

(ii) $S(t) x$ is strongly continuous for each $x$ in $H_{0}^{m}$,

(iii) $S(0)=I$ and $|S(t)|_{M} \leqq \exp \left(-k_{l} t / K_{m}\right)$ for all $t \geqq 0$,

(iv) $\lim _{h \rightarrow 0} h^{-1}(S(h)-I) x_{0}=A x_{0}$ for each $x_{0}$ in $D$, and

(v) $S(t)$ commutes with $(\lambda-A)^{-1}$ for all $\lambda \geqq 0$.

The statement (v) implies in particular that $D$ is invariant under each $S(t)$.

Having been given the initial function $u_{0}$ in $D$, we define

$$
u(t)=S(t) u_{0}, t \geqq 0
$$

and show that $u(t)$ is a solution of the generalized problem. Clearly we see $u(t)$ belongs to $H_{0}^{m}$ and $u(0)=u_{0}$. Furthermore, since $S(t)$ leaves $D$ invariant and $u_{0}$ is in $D$, it follows that $u(t)$ belongs to $D$ and thus to $H_{0}^{l}$. The function $u(t)$ is differentiable with

$$
u^{\prime}(t)=A u(t)
$$

for all $t \geqq 0$ by (i) and (iv), and hence $u^{\prime}(t)$ is in $H_{0}^{m}$.

We shall verify that $u(t)$ satisfies the equation (5). Since $D_{m}$ is dense in $H_{0}^{m}$ there is a sequence $\left\{\varphi_{n}\right\}$ in $D_{m}$ for which $\left\|\varphi_{n}-u^{\prime}(t)\right\|_{m} \rightarrow 0$ as $n \rightarrow \infty$. Now $\left\{\varphi_{n}\right\}$ is a Cauchy sequence in $H_{0}^{m}$ and it follows by (4) that $\psi_{n}=A^{-1} \varphi_{n}$ is a Cauchy sequence in the complete space $H_{0}^{l}$, so there is a $\psi$ in $H_{0}^{l}$ such that $\left\|\psi_{n}-\psi\right\|_{l} \rightarrow 0$ as $n \rightarrow \infty$. Since $A^{-1}$ is continuous we have $\psi=u(t)$. Each $\psi_{n}$ belongs to $D_{l}$, since $\varphi_{n}$ is in $D_{m}$, and furthermore $M_{0} \varphi_{n}+L_{0} \psi_{n}=0$. Now for each $\varphi$ in $C_{0}^{\infty}(G)$ we have by the continuity of $B_{M}$ and $B_{L}$

$$
\begin{aligned}
& B_{M}\left(u^{\prime}(t), \varphi\right)+B_{L}(u(t), \varphi) \\
& \quad=\lim _{a \rightarrow \infty} B_{M}\left(\varphi_{n}, \varphi\right)+\lim _{n \rightarrow \infty} B_{L}\left(\psi_{n}, \varphi\right) \\
& \quad=\lim _{n \rightarrow \infty}\left\{B_{M}\left(\varphi_{n}, \varphi\right)+B_{L}\left(\psi_{n}, \varphi\right)\right\}=\lim _{n \rightarrow \infty}\left\{\left(M_{0} \varphi_{n}, \varphi\right)_{0}+\left(L_{0} \psi_{n}, \varphi\right)_{0}\right\} \equiv 0,
\end{aligned}
$$

so the generalized problem does have a solution.

If $u(t)$ is in $D_{l}$ then by (9) $u^{\prime}(t)$ is in $D_{m}$. It follows from (5) that for every $\phi$ in $C_{0}^{\infty}(G)$

$$
\left(M_{0} u^{\prime}(t)+L_{0} u(t), \varphi\right)_{0}=0,
$$

and this implies (6). The estimate (7) is a consequence of (iii) and (8).

To show that the generalized problem has at most one solution, we let $u(t)$ be a solution of the problem with $u_{0}=0$. By linearity it suffices to show that $u(t) \equiv 0$. The differentiability of $u(t)$ in $H_{0}^{m}$ 
implies that the real valued function

$$
\alpha(t)=\operatorname{Re} B_{M}(u(t), u(t))
$$

is differentiable and

$$
\alpha^{\prime}(t)=2 \operatorname{Re} B_{M}\left(u^{\prime}(t), u(t)\right) .
$$

Since (5) is true also for all $\phi$ in $H_{0}^{l}$ by continuity, we have from $P_{2}$

$$
\alpha^{\prime}(t)=-2 \operatorname{Re} B_{L}(u(t), u(t)) \leqq 0 .
$$

But $\alpha(0)=\operatorname{Re} B_{M}(u(0), u(0))=0$, so $\alpha(t)=0$ for all $t \geqq 0$. From $P_{2}$ it follows that $u(t)=0$ for $t \geqq 0$.

\section{REFERENCES}

1. G. Barenblat, I. Zheltov, and I. Kochiva, Basic concepts in the theory of seepage of homogeneous liquids in fissured rocks, J. Appl. Math. 24 (1960), 1286-1303.

2. R. Carroll, Partial differential equations (Harper and Row, to appear)

3. A. Friedman, Partial differential equations of parabolic type, Prentice-Hall, 1964.

4. C. A. Galpern, Docklady Akad. Nauk. SSSR 119 (1958), 640-643.

5. E. Hille and R. S. Phillips, Functional analysis and semi-groups, A.M.S. Colloquium Publications, vol. 31, New York, 1957.

6. A. G. Kostachenko and G. I. Eskin, Cauchy problem for an equation of SobolevGalpern type, Trudy Moscow Math. Obshch. 10 (1961), 273-284.

7. P. D. Lax and A. Milgram, Parabolic equations, Contributions to the Theory of Partial Differential Equations, Ann. Math. Studies, no. 33 Princeton University Press, 1954, 167-190.

8. J. L. Lions, Lectures on elliptic partial differential equations, Tata Institute, Bombay, 1957.

9. R. E. Showalter, Local regularity of solutions of pseudo-parabolic partial differential equations (to appear).

10. R. E. Showalter and T. W. Ting, Pseudo-parabolic partial differential equations, (to appear, SIAM Journal)

11. S. Sobolev Izv. Akad. Nauk. SSSR Ser. Mat. 18 (1954), 3.

12. D. W. Taylor, Research on consolidation of clays, Massachusetts Institute of Technology, 1942.

13. T. W. Ting, Certain non-steady flows of second order Aluids, Arch. Rat. Mech. Anal. 14 (1963), 1-26.

14. Parabolic and pseudo-parabolic partial differential equations (to appear, J. Math. Soc. Japan).

15. T. W. Ting and R. E. Showalter, Asymptotic behavior of solutions of pseudoparabolic partial differential equations (to appear, Proc. Amer. Math. Soc.)

16. K. Yoshida, On the differentiability and representation of one-parameter semigroups of linear operators, J. Math. Soc. Japan 1 (1948), 15-21.

17. T. Zalenyak, The behavior for $t \rightarrow \infty$ of solutions of a problem of S. L. Sobolev, Soviet Math. 2 (1961), 956-958.

18. _ A problem of Sobolev, Soviet Math. 3 (1962), 1756-1759.

Received February 14, 1969.

UnIVERsity of TeXAS

Austin, Texas 



\title{
PACIFIC JOURNAL OF MATHEMATICS
}

\author{
EDITORS
}

\author{
H. ROYDEN \\ Stanford University \\ Stanford, California \\ RICHARD PIERCE \\ University of Washington \\ Seattle, Washington 98105
}

\author{
J. DUGUNDJI \\ Department of Mathematics \\ University of Southern California \\ Los Angeles, California 90007 \\ BASIL GORDON \\ University of California \\ Los Angeles, California 90024
}

\section{ASSOCIATE EDITORS}

E. F. BECKENBACH
B. H. NeumanN

F. WOLF
K. YoshidA

\section{SUPPORTING INSTITUTIONS}

\author{
UNIVERSITY OF BRITISH COLUMBIA \\ CALIFORNIA INSTITUTE OF TECHNOLOGY \\ UNIVERSITY OF CALIFORNIA \\ MONTANA STATE UNIVERSITY \\ UNIVERSITY OF NEVADA \\ NEW MEXICO STATE UNIVERSITY \\ OREGON STATE UNIVERSITY \\ UNIVERSITY OF OREGON \\ OSAKA UNIVERSITY \\ UNIVERSITY OF SOUTHERN CALIFORNIA
}

\author{
STANFORD UNIVERSITY \\ UNIVERSITY OF TOKYO \\ UNIVERSITY OF UTAH \\ WASHINGTON STATE UNIVERSITY \\ UNIVERSITY OF WASHINGTON

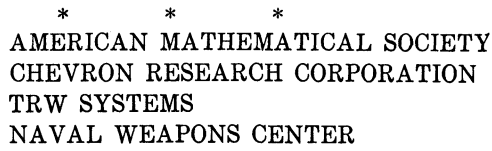

The Supporting Institutions listed above contribute to the cost of publication of this Journal, but they are not owners or publishers and have no responsibility for its content or policies.

Mathematical papers intended for publication in the Pacific Journal of Mathematics should be in typed form or offset-reproduced, double spaced with large margins. Underline Greek letters in red, German in green, and script in blue. The first paragraph or two must be capable of being used separately as a synopsis of the entire paper. It should not contain references to the bibliography. Manuscripts, in duplicate if possible, may be sent to any one of the four editors. Please classify according to the scheme of Math. Rev. 36, 1539-1546. All other communications to the editors should be addressed to the managing editor, Richard Arens, University of California, Los Angeles, California, 90024.

50 reprints are provided free for each article; additional copies may be obtained at cost in multiples of 50 .

The Pacific Journal of Mathematics is published monthly. Effective with Volume 16 the price per volume (3 numbers) is $\$ 8.00$; single issues, $\$ 3.00$. Special price for current issues to individual faculty members of supporting institutions and to individual members of the American Mathematical Society: $\$ 4.00$ per volume; single issues $\$ 1.50$. Back numbers are available.

Subscriptions, orders for back numbers, and changes of address should be sent to Pacific Journal of Mathematics, 103 Highland Boulevard, Berkeley, California, 94708.

PUBLISHED BY PACIFIC JOURNAL OF MATHEMATICS, A NON-PROFIT CORPORATION

Printed at Kokusai Bunken Insatsusha (International Academic Printing Co., Ltd.), 7-17, Fujimi 2-chome, Chiyoda-ku, Tokyo, Japan. 


\section{Pacific Journal of Mathematics}

\section{Vol. 31, No. $3 \quad$ BadMonth, 1969}

George E. Andrews, On a calculus of partition functions .................. 555

Silvio Aurora, A representation theorem for certain connected rings ............ 563

Lawrence Wasson Baggett, A note on groups with finite dual spaces ............. 569

Steven Barry Bank, On majorants for solutions of algebraic differential equations in regions of the complex plane ............................... 573

Klaus R. Bichteler, Locally compact topologies on a group and the corresponding continuous irreducible representations ......................... 583

Mario Borelli, Affine complements of divisors ....................... 595

Carlos Jorge Do Rego Borges, A study of absolute extensor spaces ............. 609

Bruce Langworthy Chalmers, Subspace kernels and minimum problems in Hilbert

spaces with kernel function ...................................... 619

John Dauns, Representation of L-groups and F-rings................. 629

Spencer Ernest Dickson and Kent Ralph Fuller, Algebras for which every

indecomposable right module is invariant in its injective envelope ...........

Robert Fraser and Sam Bernard Nadler, Jr., Sequences of contractive maps and fixed

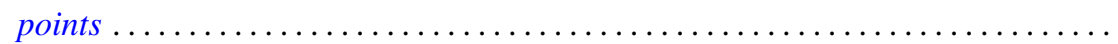

Judith Lee Gersting, A rate of growth criterion for universality of regressive

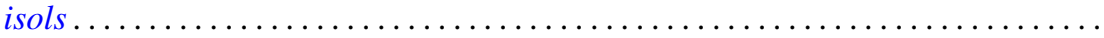

Robert Fred Gordon, Rings in which minimal left ideals are projective ............

Fred Gross, Entire functions of several variables with algebraic derivatives at certain algebraic points

W. Charles (Wilbur) Holland Jr. and Stephen H. McCleary, Wreath products of ordered permutation groups .........................

W. J. Kim, The Schwarzian derivative and multivalence .................. 717

Robert Hamor La Grange, Jr., On $(\mathrm{m}-\mathrm{n})$ products of Boolean algebras ......... 725

Charles D. Masiello, The average of a gauge ........................ 733

Stephen H. McCleary, The closed prime subgroups of certain ordered permutation

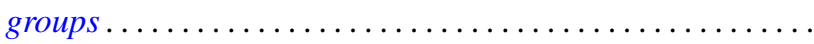

Richard Roy Miller, Gleason parts and Choquet boundary points in convolution measure algebras ...............................

Harold L. Peterson, Jr., On dyadic subspaces ........................ 773

Derek J. S. Robinson, Groups which are minimal with respect to normality being intransitive........................................... 777

Ralph Edwin Showalter, Partial differential equations of Sobolev-Galpern type . . . 787

David Slepian, The content of some extreme simplexes ................... 795

Joseph L. Taylor, Noncommutative convolution measure algebras ............. 809

B. S. Yadav, Contractions of functions and their Fourier series ............... 827

Lindsay Nathan Childs and Frank Rimi DeMeyer, Correction to automorphisms of separable algebras" ....................... 833

Moses Glasner and Richard Emanuel Katz, Correction to: "Function-theoretic degeneracy criteria for Riemannian manifolds".............

Satish Shirali, Correction to: "On the Jordan structure of complex Banach

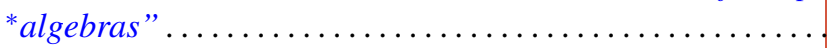

